\title{
Reducing the size of an alien segment carrying leaf rust and stripe rust resistance in wheat
}

Sofia Khazan ${ }^{\dagger}$, Anna Minz-Dub ${ }^{* \dagger}$ (D) , Hanan Sela, Jacob Manisterski, Pnina Ben-Yehuda, Amir Sharon and Eitan Millet

\begin{abstract}
Background: Leaf and stripe rusts are two major wheat diseases, causing significant yield losses. The preferred way for protecting wheat from rust pathogens is by introgression of rust resistance traits from wheat-related wild species. To avoid genetic drag due to replacement of large wheat chromosomal segments by the alien chromatin, it is necessary to shorten the alien chromosome segment in primary recombinants.

Results: Here we report on shortening of an alien chromosome segment in wheat that carries leaf and stripe rust resistance from Sharon goatgrass (Aegilops sharonensis). Rust resistant wheat introgression lines were selected and the alien region was mapped using genotyping by sequencing. Single polymorphic nucleotides (SNP) were identified and used to generate diagnostic PCR markers. Shortening of the alien fragment was achieved by induced homoeologous pairing and lines with shortened alien chromosome were identified using the PCR markers. Further reduction of the segment was achieved in tertiary recombinants without losing the rust resistance.

Conclusions: Alien chromatin in wheat with novel rust resistance genes was characterized by SNP markers and shortened by homoeologous recombination to avoid deleterious traits. The resulting wheat lines are resistant to highly virulent races of leaf and stripe rust pathogens and can be used as both resistant wheat in the field and source for gene transfer to other wheat lines/species.
\end{abstract}

Keywords: Introgression, Aegilops sharonensis, SNP, GBS, Rust, Wheat

\section{Background}

Leaf and stripe rusts are two major wheat diseases that cause tremendous annual losses in wheat worldwide. For example, from 2000 to 2004 in the USA, losses to leaf rust were estimated at over 3 million tons, worth over \$350 million [1] and losses due to stripe rust in 2003 were $3.4 \%$ or 11.7 million tons [2]. The incidence of severe rust outbreaks has intensified in the past years; primarily due to the appearance of highly virulent races that overcome wide spread rust resistance sources $[3,4]$. This situation is expected to worsen due to climatic changes that create favorable

\footnotetext{
* Correspondence: annamin1@tauex.tau.ac.il

${ }^{\dagger}$ Sofia Khazan and Anna Minz-Dub contributed equally to this work. Institute for Cereal Crops Improvement, Tel Aviv University, 69978 Tel Aviv, Israel
}

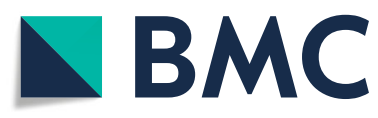

( The Author(s). 2020 Open Access This article is licensed under a Creative Commons Attribution 4.0 International License, which permits use, sharing, adaptation, distribution and reproduction in any medium or format, as long as you give appropriate credit to the original author(s) and the source, provide a link to the Creative Commons licence, and indicate if changes were made. The images or other third party material in this article are included in the article's Creative Commons licence, unless indicated otherwise in a credit line to the material. If material is not included in the article's Creative Commons licence and your intended use is not permitted by statutory regulation or exceeds the permitted use, you will need to obtain permission directly from the copyright holder. To view a copy of this licence, visit http://creativecommons.org/licenses/by/4.0/. The Creative Commons Public Domain Dedication waiver (http://creativecommons.org/publicdomain/zero/1.0/) applies to the data made available in this article, unless otherwise stated in a credit line to the data. conditions for disease outbreaks [5]. Since the high rate of pathogen virulence alterations quickly erodes the primary pool of rust resistance genes, new sources of rust resistance are needed to boost this gene pool of wheat.

Breeding for rust resistance is the most economically and environmentally safe way to control rust diseases. The conventional method used since the 1920 s to boost the wheat gene pool is introgression of new rust resistance genes from wheat-related wild species [6-8]. To date, more than 70 resistance genes against leaf rust and stripe rust originating in wheat or in its wild relatives have been identified and mapped [9]. Most of these genes confer seedling resistance although adult plant resistance (APR) genes were also identified [10, 11]. 
Despite being a rich gene pool, only few of the resistance genes were introgresed from Aegilops spp., and especially from species of section Sitopsis (diploids with $\mathrm{S}$ or modified $\mathrm{S}$ genomes). Exceptional is Aegilops speltoides that provided 6 leaf rust resistance genes $\operatorname{Lr} 28,35,364751$ and 66 [9]. Aegilops sharonensis Eig (Sharon goatgrass) was found to possess resistance against different wheat diseases including leaf, stripe and stem rusts, powdery mildew, tan spot and spot blotch [12] but has not been widely exploited [13]. In 2006, Marais et al. reported on transferring resistance to leaf rust ( $L r 56)$ and stripe rust ( $Y r 38)$ to chromosome 6A of wheat, while recently, Millet et al. [14] reported on introgressing resistance to the devastating stem rust race TTKSK (Ug99) from Ae. sharonensis to bread wheat.

One of the main challenges faced by the breeders is restricted recombination between homoeologous chromosomes, which is necessary to transferring the resistance from related species [15]. Usually, in hexaploid wheat chromosome pairing is allowed between homologous chromosomes while suppressed between homoeologous chromosomes by the Ph1, localized on the long arm of chromosome 5B [16, 17]. To allow for homoeologous pairing, deletion lines of the Ph1 locus $(p h 1 b)$ were developed to induce pairing and recombination between homoeologous chromosomes when their homologues are absent [18]. Currently, phlb is extensively used for transferring various resistance genes from the wild relatives to wheat [19].

Classically, cytogenetic analyses, such as fluorescent in situ hybridization (FISH) and genomic in situ hybridization (GISH), have been used for the detection of introgressions. These techniques are insufficiently precise to identify the translocation breakpoints [20] and require expertise which is not a common knowledge [21]. In addition, molecular markers such as DArT and microsatellites, that have been previously used to characterize the Ae. sharonensis chromatin [22-24], were too sparsely distributed to resolve the precise translocation. Moreover, the advances in sequencing technologies and the availability of a wheat reference genome [25], allowed for a more precise characterization of the alien segment [26]. Genotyping-by-sequencing (GBS) is one of the leading marker identification tools, based on reducing the genome complexity by using restriction enzymes [27]. Using GBS it is possible to isolate large number of SNPs for costefficient high density genetic mapping and development of markers for a high-throughput identification of the translocated segment [28-30].

In a previous work, a segment carrying resistance gene(s) to both leaf and stripe rust of wheat was introgressed from Ae. sharonensis into chromosome $6 \mathrm{~B}$ of bread wheat [23]. A number of wheat lines were generated with recombinant $6 \mathrm{~B}$ chromosome carrying Ae. sharonensis $6 \mathrm{~S}^{\text {sh }}$ chromosome segment of different lengths (ranging from most of the chromosome to $\sim 20 \mathrm{cM}$ ). The introgression lines showed complete resistance against a broad range of leaf and stripe rust races. However, they all possessed a chromosomal segment that is large enough to potentially affect agricultural and product desired traits, since several important genes and gene families span all over chromosome 6B. Such genes include gliadins, glutenins, grain protein content gene (GPC B1), restorer of fertility ( $R F 4)$ and supernumerary spikelet (SS) [31, 32]. The introduced segment of Ae. sharonensis might have replaced these genes, hence to avoid deleterious effect on grain and yield, the cultivated wheat genetic background should be largely restored.

The objectives of present work were to reduce the size of the introgressed segment, by derivation of secondary and tertiary recombinants, without losing the novel rust resistance, and to develop SNP-based markers for the identification of the alien segment. The new recombinants will provide a new rust resistance resource for breeding durable cultivars. The developed PCR markers will be helpful for selection of resistant progeny by breeders.

\section{Results \\ Production and molecular characterization of plants with reduced size alien introgression}

A population of 1240 plants, derived from the first cross of the ph1b/ph1b $\mathrm{BC}_{1}$ with cv. Galil (Fig. 1), were inoculated with the leaf and stripe rust isolates. A total of 594 plants were found resistant to both isolates, 45 were found resistant to one of the isolates (28 to leaf rust and 17 to stripe rust), and the other 601 plants were susceptible to both isolates. GBS analysis of 100 selected plants revealed SNPs scattered along the homoeologous recombination region on chromosome $6 \mathrm{~B}$. In order to define more precisely the location of the alien segment in specific introgression lines, the sequences of the recombinants were re-aligned to the sequence of the bread wheat cv. Chinese Spring (CS) [33]. Fisher Exact test was conducted to discover SNPs associated with resistance. Totally, 1362 SNPs were found, most of which were located in the range of $\sim 0-160 \mathrm{Mbp}$ (Fig. 2a). Twenty-six of these SNPs had $P$ values of $-\log \mathrm{P}>16$ (Fig. $2 \mathrm{~b}$ ) and were most capable to distinguish between the chromatin of Ae. sharonensis and cv. Galil. The recombined area was further divided into four regions, according to the frequency of recombination as reflected by the SNPs. Finally, we designed PCR markers from seven SNPs that span the four regions of the entire segment (Table 1), and used them to screen the remaining 520 plants that were found resistant to both isolates (Fig. 3). At first, all of the plants were screened with the two distal markers $1 \mathrm{C}$ and 4C. Presence of both markers indicated lack of recombination within the alien segment, absence of one of the markers indicated recombination on either the left side (lack of marker 1C), or the right side (lack of marker 4C) of the alien segment. We identified 38 plants 


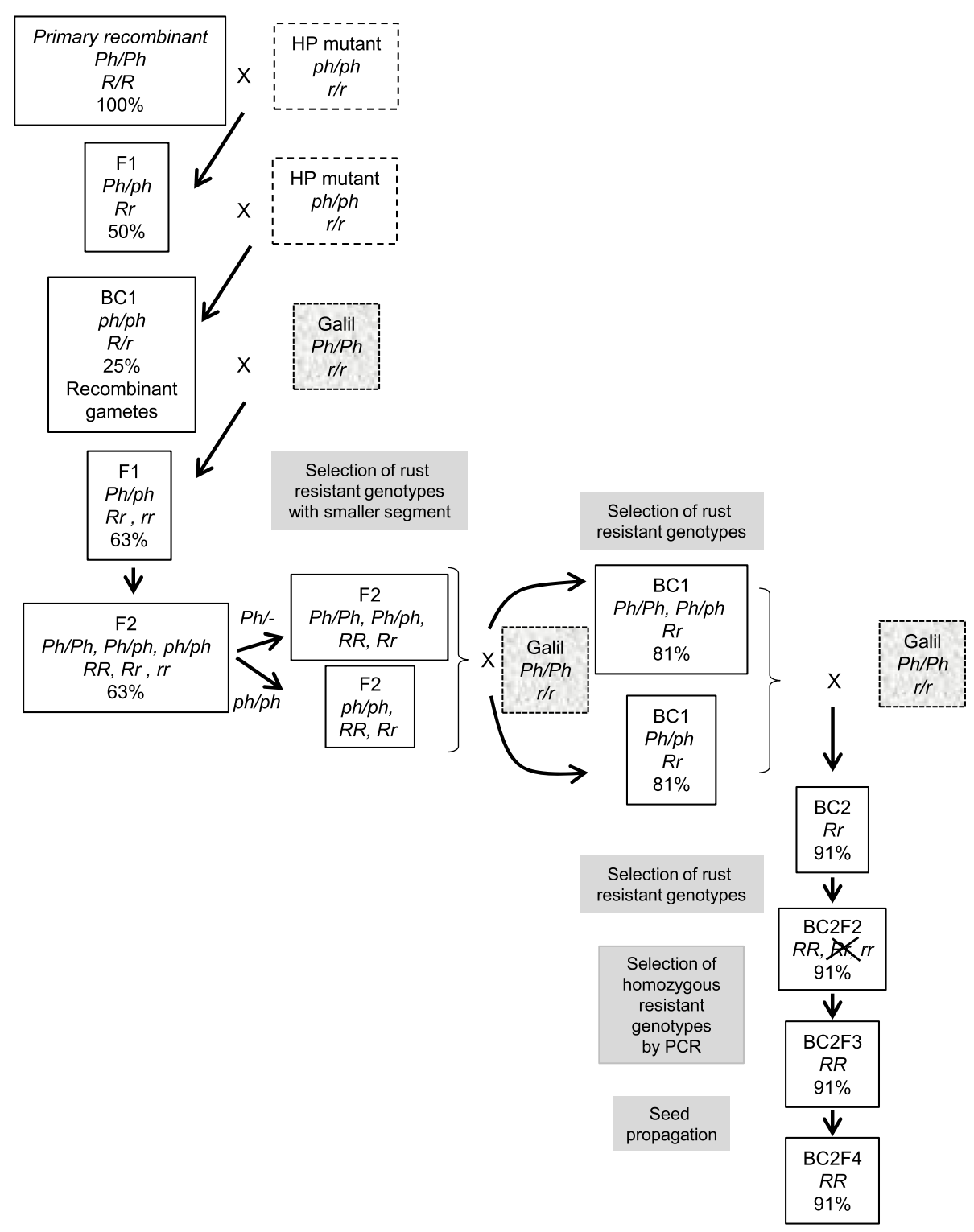

Fig. 1 Procedure for the derivation of secondary and tertiary recombinants. The procedure of the alien segment shortening is described in the Methods section. $\mathrm{R}$ and $\mathrm{r}$ denote for presence or absence of the alien resistance gene, respectively. Ph and ph denote for Phl and phib alleles, respectively. Percentage figures are calculated rate of cv. Galil chromatin

that were deficient for one of the markers and these plants were further evaluated using the remaining five PCR markers. Based on the PCR analyses we selected a set of 20 secondary recombinant (SR) plants. These plants were re-evaluated for the resistance and screened again with the PCR markers. From these plants, we selected a final set of 13 recombinant lines based on the length of the alien fragment, the introgression pattern (Fig. 4), and on their phenotypic resemblance to cv. Galil. All of these lines contained a common region of $17.4 \mathrm{Mb}$ that was detected between markers $2 \mathrm{~S} 2$ and $3 \mathrm{~S} 1$, regardless if the break point of the recombination occurred at the right or the left end. To verify this region, we developed two additional markers, 2-3HS2 and 2-3HS3 (No. 8-9 in Table 1), and used them to analyze the selected recombinants as well as randomly selected susceptible lines, which were used as a negative control. Both markers were present in all of the resistant recombinants (Fig. 4) and absent in the susceptible lines (not shown). The frequency of occurrence of each marker was calculated to indicate the rate of recombination along the chromosome segment (Fig. 5). Markers 2-3HS2 and 2-3HS3 were both present in all resistant plants, 3S1 and 3S3 were each present in 16 plants, 2S2 and 3S4 were each present in 15 plants, $4 \mathrm{C}$ in 13 plants, $2 \mathrm{~S} 1$ in 12 plants, and $1 \mathrm{C}$ was present in seven plants. In 
a

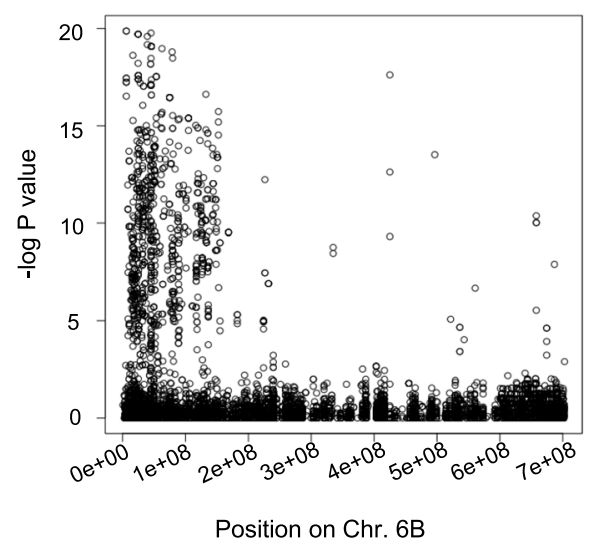

b

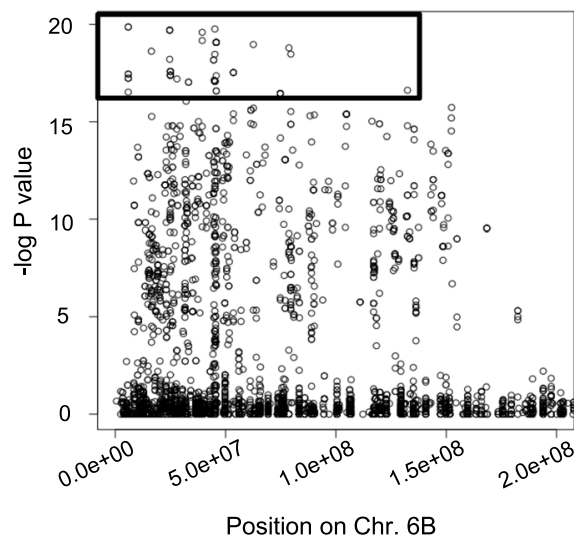

Fig. 2 Statistical analysis of chromosome 6B SNPs. - $\log P$-value of Fisher Exact test conducted on SNPs between Ae. sharonensis and bread wheat in chromosome 6B (based on alignment to CS genome). X-axis represents the position of each SNP (represented in circles) on CS genome, Y-axis is the $-\log P$-value of Fisher Exact test. a Total number of SNPs. b Zooming into the area of potential SNPs. SNPs with $-\log P>16$ are boxed

total, $2.5 \%(13 / 520)$ and $1.34 \%(7 / 520)$ of the resistant plants had a secondary recombination on the left end (indicated by lack of marker 1C) or the right end (indicated by lack of marker $4 \mathrm{C}$ ) of the introgression segment, respectively.

The final set of 13 selected SR lines were allowed to self-pollinate and between 20 and $30 \mathrm{~F}_{2}$ offspring of each SR line were evaluated for their reaction to the leaf and stripe rust isolates. PCR analysis of the resistant $F_{2}$ plants with $P h 1$ specific marker revealed 12 lines that contained the $P h 1$ allele and one line lacking it. The 12 Ph1-positive lines had different alien chromatin constitution: in seven lines the alien segment extended towards the short arm telomere, while in the remaining five lines the alien segment extended towards the long arm telomere (Fig. 4). All of these SR 6B plants were backcrossed to $\mathrm{cv}$. Galil and rust resistant (R/r) progenies were selected. In this cross, the single genotype that was found homozygous for $p h 1 b$ underwent another homoeologous pairing event and produced a tertiary $6 \mathrm{~B}$ recombinant

Table 1 PCR markers for mapping the Ae. sharonensis alien segment

\begin{tabular}{|c|c|c|c|c|c|}
\hline \multirow[t]{2}{*}{ No. } & \multirow{2}{*}{$\begin{array}{l}\text { Marker } \\
\text { name }\end{array}$} & \multicolumn{2}{|c|}{ Primer $\left(5^{\prime}-3^{\prime}\right)$} & \multirow{2}{*}{$\begin{array}{l}\text { Annealing } \\
\text { Temp }^{a}\left(C^{\circ}\right)\end{array}$} & \multirow{2}{*}{$\begin{array}{l}\text { Marker } \\
\text { size } \\
\text { (bp) }\end{array}$} \\
\hline & & Forward & Reverse & & \\
\hline 1 & $1 C$ & GGCCAGTGCAATAAACT & ATTGTAGTAAGAGTGCG & 56 & 214 \\
\hline 2 & 251 & AAAAGAAAGTTGGCCCCG & CGGCATGATTAAAACATGAGGCAA & 61 & 128 \\
\hline 3 & $2 S 2$ & TCATCGATGGGATCGAC & ATGTCCACCTGTCCCAAG & 62 & 209 \\
\hline 4 & $3 S 1$ & ATCCTATCGCTCAACATG & ACAGTTAGCTTGGCTTCA & 56 & 147 \\
\hline 5 & $3 S 3$ & TGATGGATTGGATTAAAAACTTG & GTCCTITCTCCATCTTCATC & 56 & 153 \\
\hline 6 & $3 S 4$ & GCTGCGTAAAATTAAGCA & CTITAGTCAATTCTTGGTC & 56 & 180 \\
\hline 7 & $4 C$ & CTCAATCATTTCCGTCTAC & CTACGCAACAAGGAAAACA & 57 & 191 \\
\hline 8 & $2-3 \mathrm{HS} 2$ & CAAACACCACAACAGCTATG & CAGCCCGAAGGAAAACAAT & 61 & 154 \\
\hline 9 & $2-3 \mathrm{HS} 3$ & CAATTGGCATAAGAGCCTT & CTCGACGATGATGAAGAC & 61 & 144 \\
\hline 10 & PSR2120 & TTAACGCCAGGGCATACTC & CTGCAGGAGGCGCTGGA & 58 & 232 \\
\hline 11 & Zyg_1Sh_1 & CAAACACCACAACAGCTATG & CAGCCCGAAGGAAAACAAT & 61 & 154 \\
\hline 12 & Zyg_2G_2 & CAATTGGCATAAGAGCCTG & CATAGCCATCACCACCTTG & 58 & 219 \\
\hline 13 & 3614_1 & ATCGCAAGGTGTTGTCCATT & GGCAGCTGGAAGATCAAGTC & 56 & 165 \\
\hline
\end{tabular}

In all markers, which are based on SNPs, the polymorphisms are in bold. Markers 1-7 were used to characterize the length of the segment. Markers 8-9 were used for detection of the critical area for the resistance. Marker 10 was used for selection of ph $1 b / p h 1 b$ lines. Markers 11-12 were used simultaneously for selection of plants homozygous for the segment (plants in which marker 11 was present and marker 12 was absent were selected). Marker 13 was used for the assessment of recombinant area at the distal long arm telomere area. Temperature cycling consisted of $95^{\circ} \mathrm{C}$ for $5 \mathrm{~min}$, followed by $32 \mathrm{cycles}$ of $95^{\circ} \mathrm{C}$ for 30 sec, Annealing Temperature (see table for details) for $30 \mathrm{sec}, 72{ }^{\circ} \mathrm{C}$ for $30 \mathrm{sec}$ with a final extension step at $72{ }^{\circ} \mathrm{C}$ for $5 \mathrm{~min}$

${ }^{a}$ Annealing temperature varied depending on the Taq polymerase used 


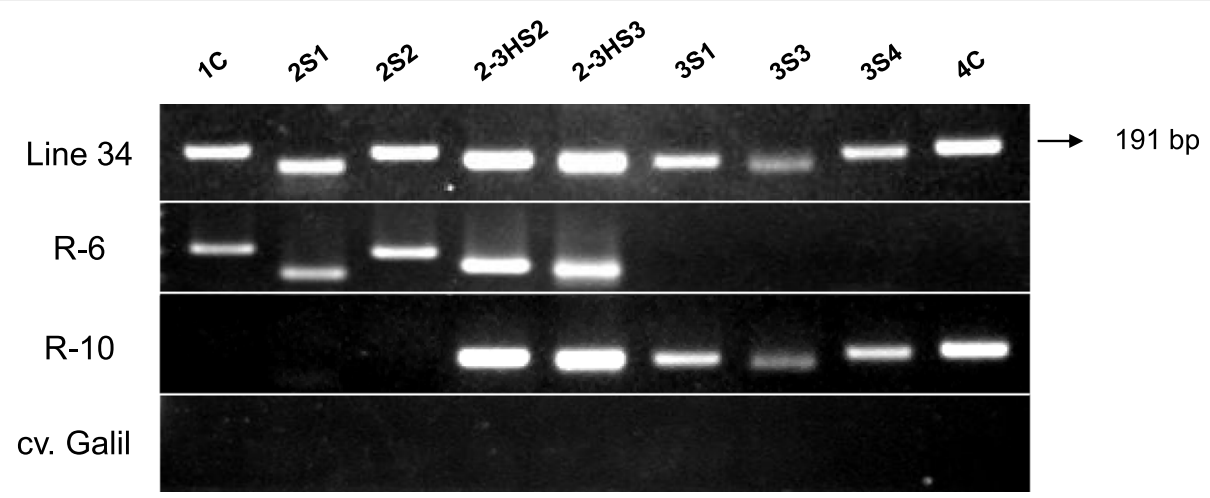

Fig. 3 Gel electrophoresis representing all of the PCR markers for assessment of the segment boundaries. cv. Galil is the susceptible elite cultivar (lack of bands represents absence of the Ae. sharonensis segment). Line 34 is one of the primary recombinants that served as a positive control. R6 is an example to a secondary recombinant with a shortened segment towards the long arm telomere, R-10 is an example to a secondary recombinant that recombined towards the short arm telomere. Four Gel images were cropped and combined together for clarity

(TR) chromosome in line P-37 (Fig. 4). All of the 12 SR lines and the single TR line were further backcrossed $\left(\mathrm{BC}_{2}\right)$ to $\mathrm{cv}$. Galil (Fig. 1) in order to recover the genetic background.

\section{Further shortening of the segment}

To further reduce the size of the alien segment we performed a cross between two $\mathrm{SR} \mathrm{BC}_{2}$ plants, one with a right arm tail (Figure S1, type a) and one with a left arm tail (Figure S1, type b). The progeny of this cross was analyzed by PCR using the diagnostic markers (Table 1) and two hybrids were selected. One hybrid (R-1018) contained an alien segment that was derived from chromosome $6 \mathrm{~B}$ in $\mathrm{SR}$ lines $\mathrm{R}-18$ and R-10 and contained the 2-3HS2 and 2-3HS3 markers (Fig. 4). The alien segment in this line was limited by markers $2-3 \mathrm{HS} 2$ and 3S4, indicating even a shorter segment than in the TR line P-37 (Fig. 4).

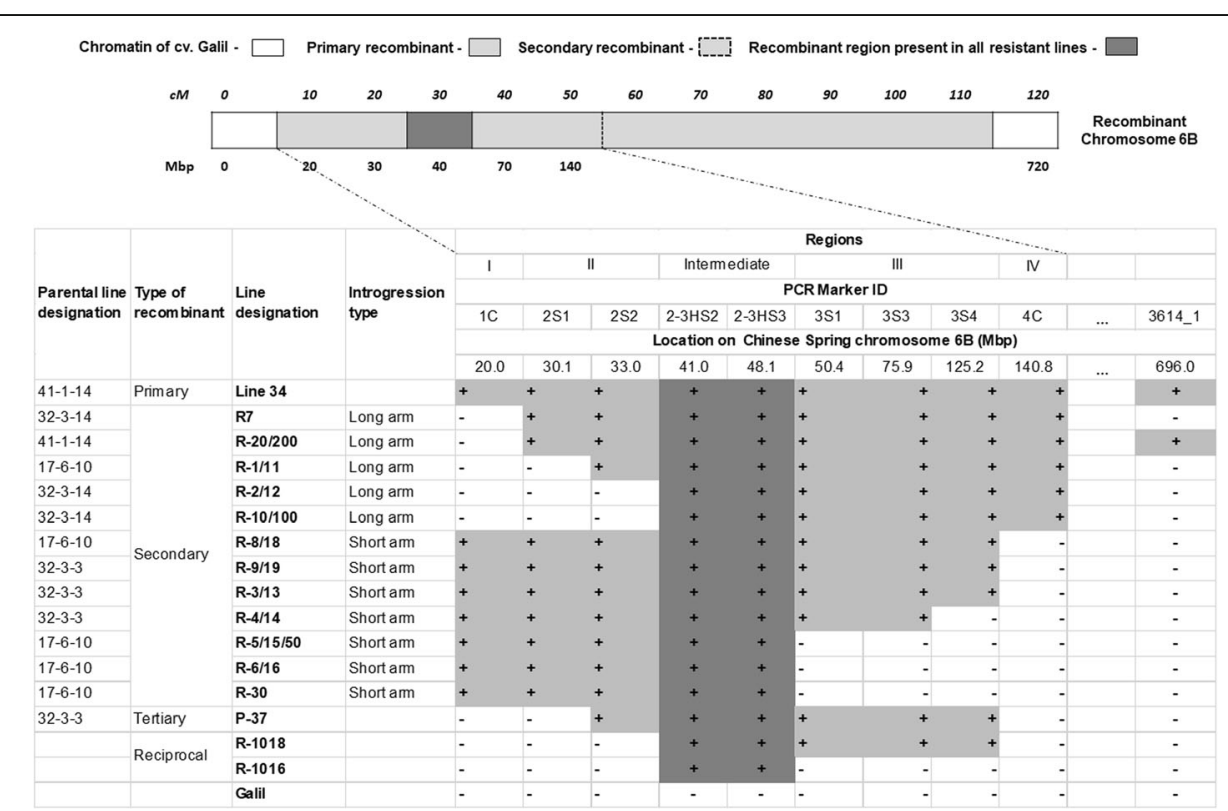

Fig. 4 Chromosome 6B constitution. Presented according to [23] and the analysis with PCR markers 1-9 (Table 1). Wheat lines presented include primary recombinant line 34, 12 secondary recombinant lines (R-), one tertiary recombinant line (P-37), R-1018 line that was derived from the cross of R-10 and R-18, and R-1016 line that was derived from the cross of R-10 and R-16. cv. Galil is the susceptible elite cultivar without the Ae. sharonensis segment. A segment spanning $0-140 \mathrm{Mb}$ of recombinant chromosome $6 \mathrm{~B}$ was divided into four regions (I-IV) restricted by markers (1C-4C). Symbols + and - indicate presence or absence of the Ae. sharonensis markers, respectively. Light grey and white colors represent presence or absence of Ae. sharonensis segment, respectively. The boxed (intermediate, dark grey color) region is the alien region present in all of the resistant recombinants. Regions I and II are left extensions (towards the short arm telomere); Regions III and IV are right extensions (towards the long arm telomere) 


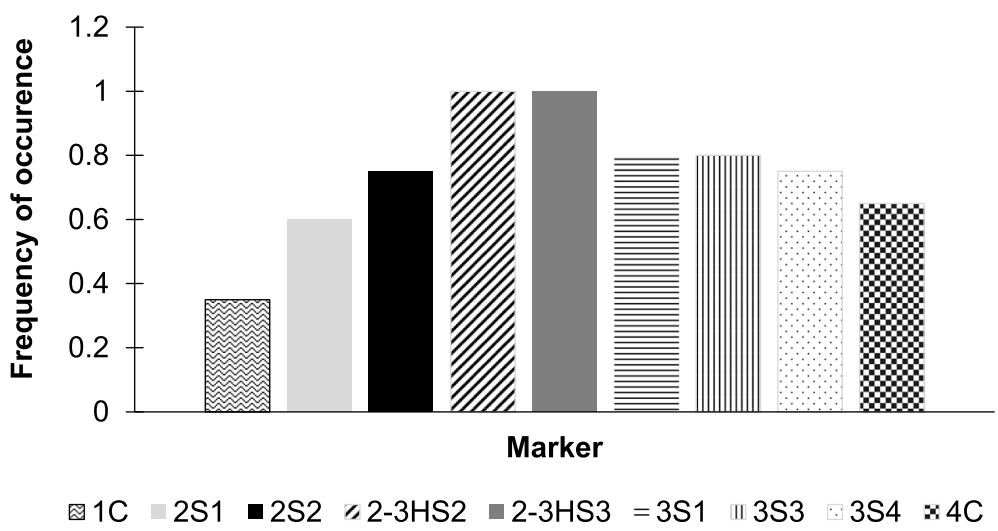

Fig. 5 Frequency of occurrence of the PCR markers for assessment of the segment. Frequencies are calculated from 20 candidates that were screened with all of the markers

The other hybrid (R-1610) contained an alien segment that was derived from chromosome $6 \mathrm{~B}$ in $\mathrm{SR}$ lines R-16 and R-10 and contained the 2-3HS2 and 2-3HS3 markers but also was limited by these markers. This hybrid possessed the shortest segment of all the introgression lines, however, self-pollinated progeny of $6 \mathrm{~B}$ heterozygous chromosome (recombinant and Galil) from crosses with cv. Galil, were unexpectedly all heterozygote for $6 \mathrm{~B}$.

\section{Marker assisted selection of homozygous plants for advanced backcrosses}

Homozygous resistant plants were selected from selfpollinated $\mathrm{BC}_{2}$ progeny by their alien segment status as follows. At least $100 \mathrm{BC}_{2} \mathrm{~F}_{2}$ plants from each SR line were screened with the PCR markers Zyg_1Sh_1 and Zyg_2G_2 (Table 1). Self-fertile lines with cv. Galil morphology, that had the desired alien chromatin (Zyg 1Sh_1 - positive) and lacked the cv. Galil PCR marker Zyg_2G_2, were selected. $\mathrm{BC}_{2} \mathrm{~F}_{3}$ seeds of the selected homozygotes of each SR line were pooled and used to produce $\mathrm{BC}_{2} \mathrm{~F}_{4}$ seeds for further experiments, including resistance to stripe rust in the field.

\section{Adult plant reaction of the secondary and tertiary recombinant lines \\ Reaction to leaf rust}

The reaction of the recombinant lines is presented in Table 2 as percentage of uredinia coverage and infection type value. A score of 3 was considered susceptible, whereas 0 to 2 reflected descending values of resistance. All the recombinant lines were highly resistant except line R-4 which segregated into highly resistant or susceptible individuals. Wheat cv. Galil had more than $80 \%$ coverage and was scored 3 IT value, hence considered as a susceptible genotype.

\section{Reaction to stripe rust}

All the recombinant lines were highly resistant (VR) with 0 coverage (R-1-2-103 and R-1-2-104 gained 0-traces) (Fig. 6) except line R-4, which segregated into 0 (VR) and $50-60 \%$ coverage (S). cv. Galil scored $30-40 \%$ (MS to $S)$ and Falchetto which was planted in every plot, scored $60-70 \%$ (S) or $70-80 \%$ (VS).

\section{Distorted segregation of the Ae. sharonensis chromatin}

Distorted segregation was observed in most of the lines in all generations (Tables 3 and 4), and the rate of homozygous resistant plants was usually lower than the expected 25\%. Moreover, resistant plants of the SR lines $\mathrm{R}-5, \mathrm{R}-6$ and R-30 yielded none or almost no homozygous plant for the alien segment and were not propagated to advanced generations. These lines typically lacked alien chromatin in regions III and IV (Fig. 4), that was present in the rest of the SR lines.

To evaluate female and male transmission, line R1610 , which yielded in self-pollination a progeny of only heterozygotes for $6 \mathrm{~B}$, was reciprocally crossed with $\mathrm{cv}$. Galil. The $F_{1}$ plants were molecularly analyzed and showed refrained female transmission of recombinant marker Zyg_1Sh_1 (Table 5), while the male transmission exceeded $64 \%$ rather than the expected $50 \%$.

\section{Discussion}

Wild plant species contain many desirable traits that can be used to improve related crop plants. However, transfer of traits from wild plant species to related crops by introgression results in replacement of large chromosome segments of the crop plant by an alien chromosomal segment and often leads to reduced yield, a phenomenon known as genetic drag. Following the initial introgression, it is therefore necessary to reduce the size of the introgression segment to minimize unwanted side effects. This task is especially challenging in wheat 
Table 2 Adult plant reaction of the recombinant lines to inoculation by leaf rust isolate \#526-24 in the greenhouse

\begin{tabular}{|c|c|c|c|c|c|c|}
\hline \multirow[t]{2}{*}{ Line } & & \multicolumn{2}{|c|}{ Flag leaf } & \multicolumn{2}{|c|}{-3 leaf } & \multirow{2}{*}{$\begin{array}{l}\text { General } \\
\text { reaction }\end{array}$} \\
\hline & & $\%$ coverage & IT value ${ }^{a}$ & $\%$ coverage & IT value ${ }^{a}$ & \\
\hline $\mathrm{R}-1(-2-103)$ & & 7.4 & 0 ; to 2 & 26.0 & 0 ; to $1+$ & R \\
\hline R-1(-2-104) & & 3.4 & 0 ; to 1 & 19.1 & 0 ; to $1-(2)$ & R \\
\hline$R-2$ & & 25.0 & 0 ; to 2 (3) & 32.2 & 0; to 2 (3) & MR \\
\hline$R-3$ & & 2.8 & 0 ; to $1+$ & 14.3 & 0 ; to $1+$ & R \\
\hline \multirow[t]{2}{*}{ R-4 } & R & 7.0 & 0 ; to 1- & 20.0 & 0 ; to $1+$ & $R$ \\
\hline & S & 70.0 & 3 & 80.0 & 3 & S \\
\hline$R-7$ & & 10.0 & 0 ; to $1+$ & 24.5 & 0 ; to 1 & $R$ \\
\hline$R-10$ & & 1.8 & 0 ; to 1 & 20.6 & 0 ; to 1- & R \\
\hline$R-16$ & & 6.2 & 0 ; to 1 & 21.0 & 0 ; to 1 (2) & $R$ \\
\hline$R-18$ & & 1.8 & 0 ; to 1 & 10.1 & 0 ; to 1 & R \\
\hline$R-19$ & & 6.7 & 0 ; to 2 & 16.9 & 0 ; to $1+$ & $R$ \\
\hline$R-20$ & & 8.2 & 0 ; to 1 (2) & 18.9 & 0 ; to $1=$ & R \\
\hline$P-37$ & & 0.8 & 0 ; to 1 & 16.6 & 0 ; to 1- & R \\
\hline Line-33 & & 2.3 & 0 ; to $1=$ & 14.1 & 0 ; to 1- & R \\
\hline Line-34 & & 3.4 & 0 ; to 1 & 10.6 & 0 ; to 1 & R \\
\hline Line-42 & & 3.4 & 0 ; to $1-$ & 16.3 & 0 ; to 1 & $R$ \\
\hline CV. Galil & & 81.7 & $3(2)$ & 63.8 & 3 & S \\
\hline
\end{tabular}

Line R-4 segregated into half resistant (R) and half susceptible (S) plants

aalues are mean of 10 plants, IT values in brackets denote rare scores on the same leaf

${ }^{\mathrm{b}}$ General reactions were as follows: 0 to 0 ;: highly resistant (HR); 0;1 to 1 : resistant (R); 1 to 2: moderately resistant (MR); 2 to $3-$ : moderately susceptible (MS); and 3- to 4: susceptible (S)

due to genetic mechanisms that prevent pairing of homoeologous chromosomes. As a result, many of the alien genes that were transferred into wheat by chromosome engineering have not been used due to the associated yield penalty [7, 34-37].
Here, we used phlb-induced homoeologous pairing to reduce the size of an alien segment carrying rust resistant genes that were introgressed into wheat from Sharon goatgrass. Our crossing procedure allowed us not only to reduce the primary segment by induction of recombination

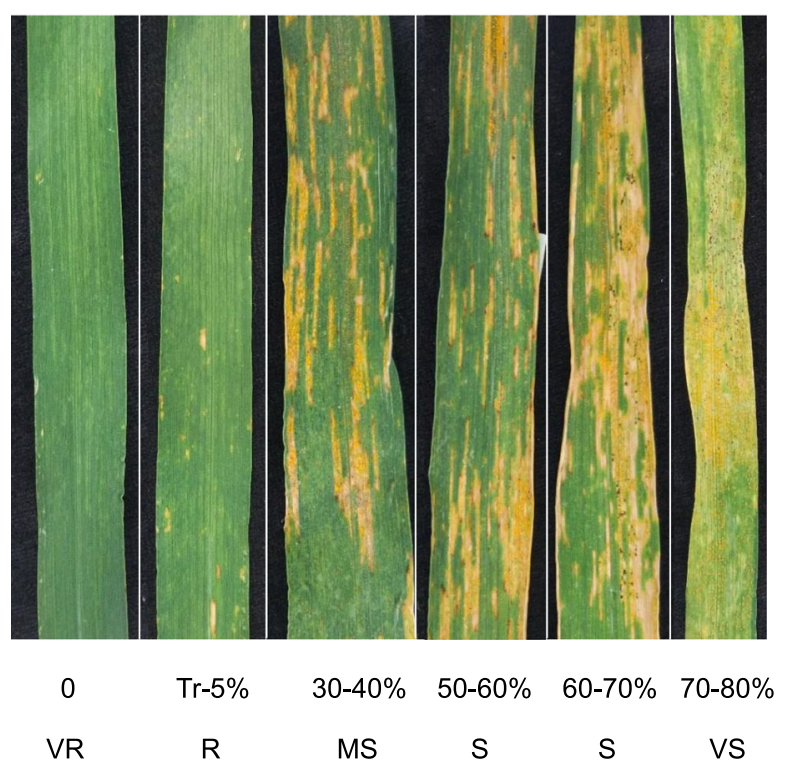

Fig. 6 Scale of reaction to field inoculation by spreader of stripe rust isolate $\# 5006$. ${ }^{*}$ R $=$ very resistant; $R=$ resistant; MS = medium susceptible; $\mathrm{S}=$ susceptible; VS = very susceptible 
Table 3 Segregation of $\mathrm{BC}_{2} \mathrm{~F}_{2}$ progeny of heterozygous alien translocation plants into rust resistant and homozygous rust resistant plants

\begin{tabular}{|c|c|c|c|c|c|c|c|c|c|}
\hline \multirow[t]{3}{*}{ Line } & \multirow{3}{*}{$\begin{array}{l}\text { No. of } \\
\mathrm{BC}_{2} \text { plants }\end{array}$} & \multirow{3}{*}{$\begin{array}{l}\text { No. of } \mathrm{BC}_{2} \mathrm{~F}_{2} \\
\text { progeny plants }\end{array}$} & \multicolumn{3}{|c|}{ Heterozygous Resistant } & \multicolumn{3}{|c|}{ Homozygous Resistant } & \multirow[t]{3}{*}{$x^{2} *$} \\
\hline & & & \multicolumn{2}{|c|}{ No. of plants } & \multirow{2}{*}{$\begin{array}{l}\% \text { of } \\
\text { plants }\end{array}$} & \multicolumn{2}{|c|}{ No. of plants } & \multirow{2}{*}{$\begin{array}{l}\% \text { of } \\
\text { plants }\end{array}$} & \\
\hline & & & Observed & Expected & & Expected & Observed & & \\
\hline R-1 & 3 & 257 & 152 & 128.5 & 59.1 & 39 & 64.25 & 15.2 & 14.27 \\
\hline R-2 & 2 & 190 & 113 & 95 & 59.5 & 17 & 47.5 & 8.9 & 26.28 \\
\hline $\mathrm{R}-3$ & 2 & 215 & 128 & 107.5 & 59.5 & 28 & 53.75 & 13.0 & 16.76 \\
\hline R-4 & 2 & 188 & 107 & 94 & 56.9 & 10 & 47 & 5.3 & 43.18 \\
\hline$R-5$ & 3 & 274 & 173 & 137 & 63.1 & 0 & 68.5 & 0 & 93.38 \\
\hline R-6 & 4 & 396 & 255 & 198 & 64.4 & 2 & 99 & 0.5 & 127.61 \\
\hline R-7 & 1 & 95 & 47 & 47.5 & 49.4 & 12 & 23.75 & 12.6 & 12.14 \\
\hline R-8 & 3 & 285 & 187 & 142.5 & 65.6 & 45 & 71.25 & 15.7 & 28.24 \\
\hline R-9 & 2 & 197 & 111 & 98.5 & 56.3 & 24 & 49.25 & 12.2 & 17.83 \\
\hline R-10 & 2 & 190 & 115 & 95 & 60.5 & 34 & 47.5 & 17.8 & 8.94 \\
\hline$R-20$ & 2 & 188 & 134 & 94 & 71.3 & 21 & 47 & 11.1 & 35.57 \\
\hline R-30 & 2 & 155 & 79 & 77.5 & 51.0 & 1 & 38.75 & 0.6 & 70.72 \\
\hline
\end{tabular}

Resistance to leaf rust pathogen was determined at seedling stage. PCR marker Zyg_1Sh_1 was used to determine presence of Ae. sharonensis resistance segment, markers Zyg_1Sh_1 and Zyg_2G_2 determined zygosity of the plants. Expected values are 50\% heterozygous, 25\% homozygous resistant and 25\% homozygous susceptible plants

${ }^{*}$ All $X^{2}$ values present significant $(p>0.05)$ deviation from the expected distribution

between the wheat DNA and the original alien segment, but also to further trim it by repeated backcrosses with the parental wheat line and selection of homozygous phlb plants at each backcross cycle. A further shortening on both sides of the segment was achieved by hybridizing two types of SR lines that paired and recombined in their overlapping region. Phenotypic screening accompanied by marker-assisted selection (MAS) facilitated the initial and further shortening of the introgression.
Different techniques were developed to enable the detection of Aegilops spp. chromatin in a wheat genetic background [20]. C-banding was used mainly to detect whole chromosome addition and substitutions. FISH and GISH were used to detect alien translocations but their resolution ability is not adequate to point precisely on the translocation breakpoints. The fact that Aegilops and Triticum spp. both have a common ancestor hampers the detection ability of substitution of Aegilops

Table 4 Segregation of 6B-chromotypes in $\mathrm{BC}_{3}$ and $\mathrm{BC}_{4}$ populations

\begin{tabular}{|c|c|c|c|c|c|c|c|c|c|c|}
\hline \multirow[t]{2}{*}{ Line } & \multicolumn{5}{|c|}{$\mathrm{BC}_{3} \mathrm{~F}_{2}$ population } & \multicolumn{5}{|c|}{$\mathrm{BC}_{4} \mathrm{~F}_{2}$ population } \\
\hline & $\begin{array}{l}\text { Total No. } \\
\text { of plants }\end{array}$ & $\begin{array}{l}\text { No. of } \\
\text { non- recombinants }\end{array}$ & $\begin{array}{l}\text { No. of } \\
\text { heterozygotes }\end{array}$ & $\begin{array}{l}\text { No. of } \\
\text { recombinant } \\
\text { homozygotes }^{\text {a }}\end{array}$ & $x^{2 *}$ & $\begin{array}{l}\text { Total No. } \\
\text { of plants }\end{array}$ & $\begin{array}{l}\text { No. of } \\
\text { non- recombinants }\end{array}$ & $\begin{array}{l}\text { No. of } \\
\text { heterozygotes }\end{array}$ & $\begin{array}{l}\text { No. of } \\
\text { recombinant } \\
\text { homozygotes }^{a}\end{array}$ & $x^{2 *}$ \\
\hline R-1 & 48 & 15 & 25 & $8(12)$ & 2.13 & 39 & 5 & 28 & $6(9.75)$ & $7.46^{*}$ \\
\hline $\mathrm{R}-2$ & 33 & 11 & 18 & $4(8.25)$ & 3.24 & 23 & 8 & 13 & $2(5.75)$ & 3.52 \\
\hline$R-3$ & 33 & 9 & 20 & $4(8.25)$ & 3.00 & 26 & 7 & 17 & $2(6.5)$ & 4.38 \\
\hline$R-4$ & 33 & 16 & 16 & $1(8.25)$ & $13.67^{*}$ & 25 & 8 & 13 & $4(6.25)$ & 1.32 \\
\hline$R-16$ & 33 & 11 & 22 & $0(8.25)$ & $11.00^{*}$ & 19 & 5 & 14 & $0(4.75)$ & $6.89^{*}$ \\
\hline $\mathrm{R}-7$ & 50 & 10 & 28 & $12(12.5)$ & 0.88 & 26 & 4 & 16 & $6(6.5)$ & 1.69 \\
\hline $\mathrm{R}-18$ & 34 & 7 & 16 & $11(8.5)$ & 1.06 & 25 & 10 & 15 & $0(6.25)$ & $9.00^{*}$ \\
\hline $\mathrm{R}-19$ & 33 & 14 & 16 & $3(8.25)$ & $7.36^{*}$ & 32 & 7 & 17 & $8(8)$ & 0.19 \\
\hline$R-10$ & 33 & 12 & 9 & $12(8.25)$ & $6.82^{*}$ & 25 & 7 & 7 & $11(6.25)$ & $6.12^{*}$ \\
\hline$R-20$ & 33 & 10 & 17 & $6(8.25)$ & 1.00 & 25 & 9 & 14 & $2(6.25)$ & 4.28 \\
\hline P-37 & 31 & 8 & 19 & $4(7.75)$ & 2.61 & 25 & 6 & 13 & $6(6.25)$ & 0.04 \\
\hline
\end{tabular}

PCR marker Zyg_1Sh_1 was used to determine presence of Ae. sharonensis resistance segment, markers Zyg_1Sh_1 and Zyg_2G_2 determined zygosity of the plants. $\mathrm{BC}_{4}$ was produced by pollinating heterozygous $\mathrm{BC}_{3}$ by $\mathrm{cv}$. Galil *Significant $(p>0.05)$ deviation from the expected distribution

a $V$ alues in brackets denote the expected number of recombinant homozygotes 
Table 5 Male and female transmission of the recombinant Ae. sharonensis Zyg_1sh_1 marker in heterozygous $F_{1}$ plants of reciprocal crosses

\begin{tabular}{lccc}
\hline Cross & $\begin{array}{l}\text { No. of } F_{1} \\
\text { progeny plants }\end{array}$ & $\begin{array}{l}\text { No. of plants with Ae. } \\
\text { sharonensis chromatin }\end{array}$ & \% of plants \\
\hline R-1610 X cv. Galil & 48 & 0 & 0 \\
cv. Galil X R-1610 & 45 & 29 & 64.4 \\
\hline
\end{tabular}

Heterozygous R-1610 plants were reciprocally crossed with cv. Galil. PCR marker Zyg_1Sh_1 was used to determine presence of Ae. sharonensis resistance segment

segment for its wheat homoeologue. Molecular approaches such as DArT [23, 24] or SSR [22] that were used to detect Ae. sharonensis chromatin were not satisfactory for a precise characterization of the introgression due to sparse or unequivocal markers. Hence, GBS was performed and confirmed the mapping of the alien segment to the $6 \mathrm{~B}$ chromosome by the previous DArT analysis [23]. Subsequent development and utilization of SNP-based molecular markers (Table 1, 1-9) assisted analysis of the introgression boundaries and selection of desired shortened secondary and tertiary recombinant lines. In particular, a $\sim 17 \mathrm{Mbp}$ region, confined by markers 2-3HS2 and 2-3HS3, was identified as necessary for the resistance as it was present in all the resistant lines and absent from the susceptible (Fig. 4). Additional dominant molecular markers allowed for phenotypic selection of homozygous plants avoiding unnecessary round of phenotypic selection (Table 1, 11-12). Since the markers are located within the alien segment and are associated with the resistance, they may also be used in future breeding programs for detection of the resistance genes. We conclude that the combination of induced homoeologous recombination by $p h 1 b$, together with crosses of non-identical SR lines, in combination with molecular analysis, considerably fosters shortening of an alien segment in wheat.

To allow homeologous pairing, the rust resistant $A e$. sharonensis line was crossed with wheat cv. CS ph1b mutant line [23]. The rust resistance was then transferred to a commercial wheat line by crossing the primary cv. CS introgression lines with the elite line cv. Galil (Fig. 1). Therefore, the $\mathrm{BC}_{2}$ generation of the $\mathrm{SR}$ and TR lines contains about $10 \%$ of $\mathrm{cv}$. CS, which needs to be further reduced by additional backcrosses to $\mathrm{cv}$. Galil prior to evaluation of the field performance of the SR and TR lines. For example, during the course of the study, we noticed that some of the introgression lines suffered from leaf chlorosis. While hybrid necrosis or chlorosis is frequent in tetraploid by hexaploid wheat hybrids, due to the action of two complementary genes [38, 39], chlorosis was not present in earlier generations in the greenhouse and emerged in field plots after three crosses to cv. Galil. Although the reason for the chlorosis remains unclear, we expect that this defect is associated with the remaining CS chromatin and that it will be eliminated in more advanced backcross generations.

Another observation indicated that in some cases the genetic segregation of the alien segment was distorted. Distorted segregation is a widespread phenomenon in plant species including wheat and its relatives [40, 41]. Distorted segregation can be observed as quantitative deviation from Mendelian segregation but can reach a total exclusion of a certain type of gametes from fertilization as in the case of pollen killer (Ki) [42] and gametocidal (Gc) genes [43]. Indeed, we observed a general reduction in transmission of gametes with recombinant $6 \mathrm{~B}$ chromosome compared to expected theoretical segregation (Tables 3 and 4). The extreme deviation from the expected ratio of homozygous resistant $\mathrm{BC}_{2} \mathrm{~F}_{2}$ progeny plants was observed in the SR lines R-5, R-6, and R-30 (Table 3). These lines have a similar constitution of the alien chromatin towards the short arm telomere and are limited by the 2-3HS3 marker (Fig. 4). In contrast, the SR line R-4, in which segregation was not so severely distorted, also contains a fragment that extends towards the short arm telomere, however in this line the segment is slightly longer as it includes marker 3S3 (Fig. 4). It is possible that an unknown factor of the wheat chromatin resides between markers 2-3HS3 and 3S4 (located between 48.1 and 125.2 Mbp on chromosome $6 \mathrm{~B}$ ) and prevents transmission of the gametes by interaction with the Ae. sharonensis chromatin on the short recombinant $6 \mathrm{~B}$ chromosome arm. Moreover, the recombinant $6 \mathrm{~B}$ chromosome was not transmitted at all through the female gametes, in the reciprocal crosses of the shortened hybrid line R-1610 and cv. Galil, resulting in no $\mathrm{F}_{1}$ progeny with Ae. sharonensis resistance segment (Table 5). Marais et al. [44] however reported on differential transmission of wheat and recombinant 6A chromosome with translocation from Ae. sharonensis, where exclusive (100\%) male transmission and reduced (35\%) female transmission of the recombinant chromosome was evident. The hypothesis that this phenomenon stems from the action of the pollen killer gene, that might be present on chromosome 6B [45] of cv. Galil but not on the recombinant chromosome that contains chromatin of cv. CS and Ae. sharonensis was rejected in our case, since male transmission was not negatively affected (Table 5). The involvement of a gametocidal gene was also rejected since it is active on both male and female gametes and should bring about a half seed set in a selfpollinating spike, which was not the case here. While the mechanism(s) behind the reduced transmission rates of the alien chromosome remain to be found, it is important to note that reduced gamete transmission is expressed only in heterozygotes and therefore it does not pose any constraints on grain production of a homozygous plant. Indeed, plants that are homozygous for the recombinant gave rise to fully fertile spikes. 


\section{Conclusions}

We demonstrated the usefulness of the ph1b mutation for induction of recombination between wheat and Ae. sharonensis chromatin, and established a working protocol for repeated trimming of an alien segment, accompanied by marker-assisted selection. Decrease in the segment size was achieved first through homoeologous recombination in background of a ph 1 mutant, and then by homologous recombination of two different types of recombinants. The procedure allowed for reduction of the introgressed segment together with potential negative effects on grain yield and quality, without harming the rust resistance.

We also showed here the efficiency of the GBS method in the identification of SNPs that can be used for efficient selection of the resistant recombinants in future breeding programs.

\section{Methods}

In this study, we aimed to reduce the size of the introgressed alien segment from rust resistant primary recombinants. The primary recombinant lines were produced using ph1b induction of homoeologous pairing between bread wheat cv. Chinese Spring (CS) and Sharon goatgrass chromosomes followed by backcrossing to the recurrent wheat parent cv. Galil [23]. Here, to reduce the size of the alien segment, we produced secondary and tertiary recombinants using the ph1b mutant, without losing the novel rust resistance.

\section{Plant material}

The recombinant lines that were selected for this work were produced by E. Millet [23] and their seeds are deposited in the Harold and Adele Lieberman Germplasm Bank at Tel Aviv University; their 6B chromosome constitution is presented in Table 6. The homoeologous pairing ph1b mutant (HP) in the genetic background of cv. CS was originally obtained personally from the late E.R. Sears. Wheat cv. Galil is an elite Israeli spring wheat cultivar obtained from the "Hazera" seed company. It possesses the leaf rust resistance $\operatorname{Lr} 26$ and stripe rust resistance $\operatorname{Yr} 19$ genes but it is susceptible to the leaf and the stripe rust isolates that were used in this research.

\section{Pathogens}

We used the leaf rust isolate \#526-24 and stripe rust isolate \#5006 from the stocks of the Institute for Cereal Crops Improvement. The virulence / avirulence (V / Av) formula of these isolates is $\operatorname{Lr} 1,3,24,26,10,18,21,23,15$ / Lr2a,2c,9,16,3 ka,11,17,30 and $Y r 6,7,8,9,11,12,17,19, s k, 18$, A / Yr1,5,10,15,24,26,sp, for isolates \#526-24 and \#5006, respectively. Both of these isolates were used to select resistant progenies at the seedling stage and to evaluate adult plant resistance. Both isolates are virulent to $\mathrm{cv}$. Galil and represent highly virulent pathogen races.

\section{Inoculation and disease evaluation Seedling stage}

Seedlings of each generation were tested and selected for susceptibility to leaf and stripe rusts. Plants were grown in small pots in a temperature-controlled greenhouse at $22 \pm 2{ }^{\circ} \mathrm{C}$. Seven to 10 days-old seedlings were inoculated by spraying to runoff with $\sim 1 \mathrm{mg}$ of urediniospores suspended in $800 \mu \mathrm{l}$ of lightweight mineral oil Soltrol ${ }^{\bullet} 170$ Isoparaffin (ChevronPhillips). After evaporation of the oil, the leaf rust-inoculated plants were maintained in a dew chamber at $18{ }^{\circ} \mathrm{C}$ for $24 \mathrm{~h}$ and then moved to a greenhouse. Stripe rust-inoculated plants were maintained in a dew chamber with $9^{\circ} \mathrm{C}$ for $16 \mathrm{~h}$ in dark followed by $15^{\circ} \mathrm{C}$ in light and then moved to a growth chamber with $15^{\circ} \mathrm{C}$ and $12 \mathrm{~h}$ light / $12 \mathrm{~h}$ dark regime. Symptoms were scored 10-12 days post-inoculation for infection type (IT) on a standard 0-4 scale [46]. ITs of 0-2 were considered indicative of a resistant response, while scores of 3-4 were considered as a susceptible response.

\section{Adult plants}

Leaf rust in the greenhouse Single homozygous $\mathrm{BC}_{4} \mathrm{~F}_{4}$ primary- and $\mathrm{BC}_{2} \mathrm{~F}_{4}$ secondary-recombinant plants were grown in $5 \mathrm{~L}$ pots placed in a cooled greenhouse and sprayed with urodiniospores at seventh leaf stage (stem elongation, stage 3 - Zadoks scale, [47]). Four groups of plants, each containing two pots for each genotype, were inoculated similarly to the seedling inoculation. Disease level was evaluated after spike emergence, about 3 weeks post inoculation.

Stripe rust in the field Seeds of the same primary and secondary recombinants that were used in seedling assays were planted in nursery plots under field conditions. Each plot (single genotype) consisted of four $1 \mathrm{~m}$ rows $20 \mathrm{~cm}$ apart and a single margin row $40 \mathrm{~cm}$ apart of the spreader cv. Falchetto. The Falchetto plants were inoculated, at seventh leaf stage, with urediniospores six times between January 14 to February 5, by either brushing the upper leaves with a bundle of highly infected leaves, or by dusting the plants with a mixture of urediniospores and talc using a manual air pump. High humidity and cool nights prevailed in the experimental area during this period.

\section{Shortening the alien segment}

Secondary recombinants (SR) with shortened alien segment were obtained by induction of homoeologous recombination in hybrids between the primary recombinants and the wheat cv. Galil, followed by phenotyping and molecular selection as depicted in Fig. 1 
Table 6 Source of secondary recombinant seeds hybridized to cv. Galil

\begin{tabular}{|c|c|c|c|c|c|}
\hline \multicolumn{2}{|r|}{ Primary recombinant lines } & \multicolumn{3}{|c|}{ Selected $\mathrm{BC}_{1}$ (to the HP mutant) } & \multirow{2}{*}{$\begin{array}{l}\text { Number of } F_{1} \text { seeds }\left(B C_{1}\right. \\
\text { crossed with cv. Galil) })^{d}\end{array}$} \\
\hline Line designation & Introgression size on chromosome $6 \mathrm{~B}^{\mathrm{a}}(\mathrm{CM})$ & Inoculating pathogen & Infection type ${ }^{b}$ & General reaction ${ }^{c}$ & \\
\hline$R Y-32-3-3$ & $30[7]-107[120]$ & Leaf rust & 0 & $\mathrm{HR}$ & 44 \\
\hline RL-17-6-10 & $33[7]-107[120]$ & Leaf rust & $0 ;-1,1+$ & $\mathrm{R}$ & 380 \\
\hline RY-41-1-14 & $30[7]-107[120]$ & Leaf rust & $1-1+$ & $\mathrm{R}$ & 136 \\
\hline RY-32-3-14 & $33[13]-87$ & Leaf rust & $1-2,2+$ & MR & 33 \\
\hline RY-14-1-7 & $38-87$ & Leaf rust & $0 ;-1$ & $\mathrm{R}$ & 37 \\
\hline RY-32-3-3 & $30[7]-107(120]$ & Stripe rust & $0 ; 1=$ & $\mathrm{R}$ & 116 \\
\hline RL-17-6-10 & $33[7]-107[120]$ & Stripe rust & 0 & $\mathrm{HR}$ & 234 \\
\hline RY-32-3-14 & $33[13]-87$ & Stripe rust & 0 & $\mathrm{HR}$ & 362 \\
\hline RY-14-1-7 & $38-87$ & Stripe rust & $0 ; 1-$ & $\mathrm{R}$ & 58 \\
\hline
\end{tabular}

${ }^{a}$ Numbers are based on presence of Ae. sharonensis DArT markers or absence of wheat markers. Numbers in square brackets are based on absence of cv. Galil markers in the recombinant line and in CS [23]. RY and RL denote for resistance to stripe rust or to leaf rust, respectively, by which these lines were first selected ${ }^{b}$ Infection types scored according to a 0 to 4 scale. Minus (-) and double minus (=) notations indicate reduced and highly reduced sporulation of uredinia, respectively, compared to classically described infection types

'General reactions were as follows: 0 to $0 ;:$ highly resistant (HR); 0;1 to 1: resistant (R); 1 to 2: moderately resistant (MR); 2 to $3-:$ moderately susceptible (MS); and 3- to 4: susceptible (S)

${ }^{\mathrm{d}}$ Reflects apparent heterozygous secondary recombinant $6 \mathrm{~B}$ chromosome

and Figure S1. Briefly, selected primary recombinants with different sizes of alien introgression on chromosome 6B (Table 6) were pollinated by the HP mutant and the $F_{1}$ offspring were backcrossed to the HP mutant. Rust resistant plants that were homozygous for ph1b were selected and pollinated by cv. Galil. The resulting hybrids were screened for reaction to both pathogens and $6 \mathrm{~B}$ chromosome constitution of resistant plants was determined using molecular markers (Table 1). Plants with reduced size of the alien segment, compared to the fragment size in parental primary recombinants, were selected and allowed to selfpollinate. Selected rust resistant $F_{2}$ plants were characterized for their Ph1 genotype. Ph1/- were considered secondary recombinants, while homozygous $p h 1 b$ were allowed for another recombination event. Both groups of plants were pollinated by cv. Galil to produce $\mathrm{BC}_{1}$ progeny. Chromosome $6 \mathrm{~B}$ of $\mathrm{BC}_{1}$ plants of the latter group was molecularly analyzed and one tertiary recombinant was obtained. All of the rust resistant $\mathrm{BC}_{1}$ recombinants were backcrossed again to cv. Galil. $\mathrm{BC}_{2}$ plants that were resistant to the leaf and stripe rust isolates were self-pollinated. Resistant $\mathrm{BC}_{2} \mathrm{~F}_{2}$ progeny of each recombinant that are also homozygous for the $\mathrm{SR} 6 \mathrm{~B}$ chromosome were selected. $\mathrm{BC}_{2} \mathrm{~F}_{3}$ seeds of these plants were pooled and used for seed propagation in the greenhouse.

\section{Further shortening of the segment}

The secondary recombinant (SR) line R-10, in which the alien chromatin extended towards the telomere of the long chromosome arm (right extension; Figure S1, type a) and SR line R-18 in which the alien chromatin extended towards the telomere of the short chromosome arm (left extension; Figure S1, type b) were crossed aiming to curtail the extensions towards the telomeres while maintaining the alien region around the resistance locus (Figure S1, tertiary recombinant). The hybrids were pollinated by cv. Galil and their desired offspring were selected by the molecular markers (Table 1).

\section{Molecular characterization of the alien segment DNA extraction}

Leaves were collected and stored at $-80^{\circ} \mathrm{C}$. Frozen leaf samples $(50 \mathrm{mg})$ were freeze-dried using Lyophilizer (Blue Wave, BW-10-ORD) for $16 \mathrm{~h}$, and grinded for $1 \mathrm{~min}$ at $1500 \mathrm{rpm}$, using two $1 / 8^{\prime \prime}$ and one $3 / 16^{\prime \prime}$ stainless steel beads in a Tissue-lyser (GenoGrinder). DNA was extracted using E-Z 96 Plant DNA Kit (Omega) (for PCR analysis), or using DNeasy Plant mini kit (Qiagen) (for GBS), according to manufacturer instructions.

\section{Selection of ph1b mutants}

The presence of the Ph1 allele was detected by marker PSR2120 (No. 10 in Table 1) according to Qu et al. [48]. Plants deficient for the corresponding band were considered as $p h 1 b / p h 1 b$ mutants.

\section{Genotyping by sequencing (GBS)}

GBS was performed on 100 samples comprised of cv. Galil, the HP mutant, and 74 resistant and 24 susceptible secondary recombinant $F_{1}$ plants (Fig. 1), most of which were derived from the primary recombinant line RY-323-14 [23]. DNA was isolated from leaves of young plants (1 month old) as described above. Sequencing was performed according to a modified Restriction site Associated DNA Sequencing (RAD-Seq) method [27] at AgriLife Genomics (Texas). Briefly, genomic DNA was 
digested with the restriction enzyme PstI and approximately $110 \mathrm{bp}$ were sequenced from both sides of the fragments. For sequencing, single end V4 chemistry with 125 bp kit were used on Illumuna Hiseq 2500 resulting in $40 \mathrm{M}$ reads per sample of cv. Galil and the HP mutant, and $8 \mathrm{M}-10 \mathrm{M}$ reads per sample for the rest of the recombinants. Raw data were analyzed by NRGene Ltd. (Ness Ziona, Israel), using the newly assembled wild emmer 'Zavitan' genome [25] as a reference.

\section{Development of molecular markers for the alien segment}

According to the frequency of recombination events, single nucleotide polymorphisms (SNPs) between $A e$. sharonensis and wheat sequences were mapped along the introgression region. Based on the SNPs, nine PCR primers (markers) were designed following the instructions mentioned at Ayyadevara et al. [49] (No. 1-9 in Table 1). An online available database was used to check for repetitive elements [50].

Conversion from the wild emmer map sequence to CS map sequence and SNPs detection was accomplished as follows: raw reads were de-multiplexed using GBSX [51]. Reads of each genotype were aligned to chromosome $6 \mathrm{~B}$ of the CS reference genome using Burrows-Wheeler Aligner (BWA) [52]. Samtools package [53] was used to pileup the individual alignment files into one pileup file that was used by bcftools call function [54] to call the SNPs. VariantAnnotation $\mathrm{R}$ package [55] was used to read the SNP data into $\mathrm{R}$ environment. For each SNP a Fisher Exact test was conducted using a 2X2 contingency table of resistant and susceptible genotypes against the origin of the SNP allele (CS as "reference" SNP or the alien "alternative"). - $\log P$-values of the Fisher test were plotted against the position of the corresponding SNP. Higher $-\log P$-values (i.e. lower $P$-values) indicated the probability of the SNPs-resistance association to be non-random. SNPs with $-\log P>16$, were assumed to be associated with the resistance locus.

\section{Homozygosity of the alien segment}

PCR SNP-based primers (markers) were developed to detect the presence/absence of both Ae. sharonensis and cv. Galil genotypes (accordingly, presence of cv. Galil marker in a rust resistant plant indicated the heterozygosity of the segment) (No. 11-12 in Table 1).

\section{Supplementary information}

Supplementary information accompanies this paper at https://doi.org/10 1186/s12870-020-2306-9.

Additional file 1: Figure S1. Schematic presentation of the recombinant $6 \mathrm{~B}$ chromosome from primary to tertiary stages. Primary recombinant contains chromatin of Galil and Ae.sharonensis origins. Secondary recombinants present significantly shortened Ae.sharonensis chromatin either from the long or the short arm of the chromosome. A cross between the two types of secondary recombinants produced further shortened tertiary recombinant.

Additional file 2.

Additional file 3 .

Additional file 4.

Abbreviations

CM: Centimorgan; CS: Chinese Spring; GBS: Genotyping by sequencing; HP: Homoeologous pairing ph1b mutant; SNP: Single nucleotide polymorphism; SR: Secondary recombinant; TR: Tertiary recombinant

\section{Acknowledgements}

Not applicable.

\section{Authors' contributions}

SK and AMD collected data, performed disease phenotypic analyses, designed and performed the genetic and molecular analyses. HS analyzed the GBS data. JM and PBY performed rust disease inoculations and analyses. EM conceived the project, guided the analyses and performed plant introgressions. AS guided the analyses. SK, AMD, EM and AS wrote the manuscript. All authors read and approved the final manuscript.

\section{Funding}

We thank the TAU Technology Innovation Momentum Fund, led by Ramot at Tel Aviv University for their kind financial support in this project. The funding did not have influence on the design of the study, collection, analysis, interpretation of data or writing of the manuscript.

\section{Availability of data and materials}

The data that support the findings of this study are available from NRGene, but restrictions apply to the availability of these data, which were used under license for the current study, and so are not publicly available. Data are however available from the authors upon reasonable request and with permission of NRGene.

Ethics approval and consent to participate

Not applicable.

\section{Consent for publication}

Not applicable.

Competing interests

The authors declare that they have no competing interests.

Received: 29 October 2019 Accepted: 24 February 2020

Published online: 09 April 2020

\section{References}

1. Huerta-Espino J, Singh RP, German S, McCallum BD, Park RF, Chen WQ, Bhardwaj SC, Goyeau H. Global status of wheat leaf rust caused by Puccinia triticina. Euphytica. 2011;179:143-60.

2. Chen XM. Epidemiology and control of stripe rust [Puccinia striiformis $\mathrm{f}$. $\mathrm{sp}$. tritici] on wheat. Can J Plant Pathol. 2005:27:314-37.

3. Hovmøller MS, Walter S, Bayles RA, et al. Replacement of the European wheat yellow rust population by new races from the centre of diversity in the near-Himalayan region. Plant Pathol. 2016;65:402-11.

4. Liu T, Wan A, Liu D, Chen X. Changes of races and virulence genes in Puccinia striiformis f. sp. tritici, the wheat stripe rust pathogen, in the United States from 1968 to 2009. Plant Dis. 2017;101:1522-32.

5. Lyon B, Broders K. Impact of climate change and race evolution on the epidemiology and ecology of stripe rust in central and eastern USA and Canada. Can J Plant Pathol. 2017:39:385-92.

6. Chhuneja P, Kaur S, Dhaliwal HS. Introgression and exploitation of biotic stress tolerance from related wild species in wheat cultivars. In: Rajpal VR, Rao SR, Raina SN, editors. Molecular breeding for sustainable crop improvement, vol 2. Switzerland: Springer International Publishing; 2016. p. 269-24

7. Dempewolf H, Baute G, Anderson J, Kilian B, Smith C, Guarino L. Past and future use of wild relatives in crop breeding. Crop Sci. 2017;57:1070-82. 
8. Ellis JG, Lagudah ES, Spielmeyer W, Dodds PN. The past, present and future of breeding rust resistant wheat. Front Plant Sci. 2014;5:641.

9. Mclntosh RA, Dubcovsky J, Rogers JW, Morris CF, Appels R, Xia XC. Catalogue of gene symbols for wheat: 2011 supplement. Annual wheat newsletter; 2010. p. 57

10. Gu L, Si W, Zhao L, Yang S, Zhang X. Dynamic evolution of NBS-LRR genes in bread wheat and its progenitors. Mol Genet Genomics. 2015;290:727-38.

11. Steuernagel B, Periyannan SK, Hernández-Pinzón I, Witek K, Rouse MN, Yu G, Hatta A, Ayliffe M, Bariana H, Jones JD, Lagudah ES. Rapid cloning of disease-resistance genes in plants using mutagenesis and sequence capture. Nat Biotechnol. 2016;34:652.

12. Olivera PD, Kolmer JA, Anikster Y, Steffenson BJ. Resistance of Sharon Goatgrass (Aegilops sharonensis) to fungal diseases of wheat. Plant Dis. 2007; 91:942-50.

13. Olivera PD, Steffenson BJ. Aegilops sharonensis: origin, genetics, diversity, and potential for wheat improvement. Botany. 2009:87:740-56.

14. Millet E, Steffenson BJ, Prins R, Sela H, Przewieslik-Allen AM, Pretorius ZA. Genome targeted introgression of resistance to African stem rust from Aegilops sharonensis into bread wheat. Plant Genome. 2017;10. https://doi. org/10.3835/plantgenome2017.07.0061.

15. Wulff BB, Moscou MJ. Strategies for transferring resistance into wheat: from wide crosses to GM cassettes. Front Plant Sci. 2014;5:692.

16. Riley R, Chapman V. Genetic control of the cytologically diploid behaviour of hexaploid wheat. Nature. 1958;182:713-5.

17. Sears ER, Okamoto M. Intergenomic chromosome relationships in hexaploid wheat. Proc Xth Internat Congr Genet Montreal. 1958;2:258-9.

18. Sears ER. A wheat mutation conditioning an intermediate level of homoeologous chromosome pairing. Can J Genet Cytol. 1982;24:715-9.

19. Kilian B, Mammen K, Millet E, Sharma R, Graner A, Salamini F, Hammer K, Ozkan H. Aegilops. In: Kole C, editor. Wild crop relatives: genomic and breeding resources, cereals. Berlin: Springer; 2011. p. 1-76.

20. Kwiatek MT, Kurasiak-Popowska D, Mikołajczyk S, Niemann J, Tomkowiak A, Weigt D, Nawracała J. Cytological markers used for identification and transfer of Aegilops spp. chromatin carrying valuable genes into cultivated forms of Triticum. Comp Cytogen. 2019;13:41-59.

21. Keilwagen J, Lehnert H, Berner T, Beier S, Scholz U, Himmelbach A, Stein N, Badaeva ED, Lang D, Kilian B, Hackauf B. Detecting large chromosomal modifications using short read data from genotyping-by-sequencing. Front Plant Sci. 2019;10:1133

22. Marais GF, Badenhorst PE, Eksteen A, Pretorius ZA. Reduction of Aegilops sharonensis chromatin associated with resistance genes $L r 56$ and Yr38 in wheat. Euphytica. 2010;171:15-22.

23. Millet E, Manisterski J, Ben-Yehuda P, Distelfeld A, Deek J, Wan A, Chen X, Steffenson $B J$. Introgression of leaf rust and stripe rust resistance from Sharon goatgrass (Aegilops sharonensis Eig) into bread wheat (Triticum aestivum L.). Genome. 2014;57:1-8.

24. Olivera PD, Kilian A, Wenzl P, Steffenson BJ. Development of a genetic linkage map for Sharon goatgrass (Aegilops sharonensis) and mapping of a leaf rust resistance gene. Genome. 2013:56:367-76.

25. Avni R, Nave M, Barad O, Baruch K, Twardziok SO, Gundlach H, Jordan KW, et al. Wild emmer genome architecture and diversity elucidate wheat evolution and domestication. Science. 2017;357:93-7.

26. Rasheed A, Mujeeb-Kazi A, Ogbonnaya FC, He Z, Rajaram S. Wheat genetic resources in the post-genomics era: promise and challenges. Ann Bot. 2017; 121:603-16.

27. Elshire RJ, Glaubitz JC, Sun Q, Poland JA, Kawamoto K, Buckler ES, Mitchell SE. A robust, simple genotyping-by-sequencing (GBS) approach for high diversity species. PLoS One. 2011;6:e19379.

28. He J, Zhao X, Laroche A, Lu ZX, Liu H, Li Z. Genotyping-by-sequencing (GBS), an ultimate marker-assisted selection (MAS) tool to accelerate plant breeding. Front Plant Sci. 2014;5:484.

29. Qureshi N, Bariana H, Forrest K, Hayden M, Keller B, Wicker T, Faris J, Salina E, Bansal U. Fine mapping of the chromosome $5 B$ region carrying closely linked rust resistance genes Yr47 and Lr52 in wheat. Theor Appl Genet. 2017;130:495-504

30. Rasheed A, Xia X. From markers to genome-based breeding in wheat. Theor Appl Genet. 2019;132:767-84

31. Appels R, Eversole K, Feuillet C, Keller B, Rogers J, Stein N, Pozniak CJ, Choulet F, Distelfeld A, Poland J, Ronen G. Shifting the limits in wheat research and breeding using a fully annotated reference genome. Science. 2018;361(6403):eaar7191.
32. Nadolska-Orczyk A, Rajchel IK, Orczyk W, Gasparis S. Major genes determining yield-related traits in wheat and barley. Theor Appl Genet. 2017; 130:1081-98

33. Reference A: IWGSC RefSeq v1.0 Database. https://wheat-urgi.versailles.inra. fr/Seq-Repository. Accessed 2 Sept 2016.

34. McIntosh RA. Alien sources of disease resistance in bread wheats. In: Sasakuma T, Kinoshita T, editors. Proc. of Dr. H. Kihara Memorial Int. Symp. on cytoplasmic engineering in wheat. Nuclear and organellar genomes of wheat species. Yokohama: Yokohama Foundation for the Advacement of Life Science; 1991. p. 320-32.

35. Niu Z, Klindworth DL, Yu G, et al. Development and characterization of wheat lines carrying stem rust resistance gene Sr43 derived from Thinopyrum ponticum. Theor Appl Genet. 2014;127:969-80.

36. Zhang P, Dundas IS, Xu SS, Friebe B, Mclntosh RA, Raupp WJ. Chromosome engineering techniques for targeted introgression of rust resistance from wild wheat relatives. In: Periyannan S, editor. Wheat rust diseases, methods and protocols. : Springer, Switzerland; 2017a. p. 163-172.

37. Zhang W, Cao Y, Zhang M, et al. Meiotic homoeologous recombinationbased alien gene introgression in the genomics era of wheat. Crop Sci. 2017b;57:1189-98.

38. Caldwell RM, Compton LE. Complementary lethal genes in wheat causing a progressive lethal necrosis of seedlings. J Hered. 1943:34:66-70.

39. Hermsen JGT. Sources and distribution of the complementary genes for hybrid necrosis in wheat. Euphytica. 1963:12:147-60.

40. Liu X, Guo L, You J, et al. Progress of segregation distortion in genetic mapping of plants. Res J Agron. 2010;4:78-83.

41. Wingen LU, West $C$, Leverington-Waite $M$, et al. Wheat landrace genome diversity. Genetics. 2017;205:1657-76.

42. Sears ER, Loegering WQ. A pollen-killing gene in wheat. Genetics. 1961;46: 897.

43. Tsujimoto $\mathrm{H}$. Two new sources of gametocidal genes from Aegilops longissima and Ae. sharonensis. Wheat Inf Serv. 1994;79:42-6.

44. Marais GF, McCallum B, Marais AS. Leaf rust and stripe rust resistance genes derived from Aegilops sharonensis. Euphytica. 2006;149:373-80.

45. Loegering WQ, Sears ER. Distorted segregation of stem rust resistance of Timstein wheat caused by a pollen-killing gene. Can J Genet Cytol. 1963;5:65-72.

46. Mclntosh RA, Wellings CR, Park RF. Wheat rusts: an atlas of resistance genes. Australia: CSIRO Publishing; 1995

47. Zadoks JC, Chang TT, Konzak CF. A decimal code for the growth stages of cereals. Weed Res. 1974;14:415-21.

48. Qu LJ, Foote TN, Roberts MA, Money TA, Aragon-Alcaide L, Snape JW, Moore G. A simple PCR-based method for scoring the phib deletion in wheat. Theor Appl Genet. 1998:96:371-5.

49. Ayyadevara S, Thaden JJ, Reis RJS. Discrimination of primer 3'-nucleotide mismatch by Taq DNA polymerase during polymerase chain reaction. Anal Biochem. 2000;284:11-8.

50. Reference B: GrainGenes. https://wheat.pw.usda.gov/ITMI/Repeats/ blastrepeats3.html. Accessed 2 Sept 2016.

51. Herten K, Hestand MS, Vermeesch JR, Van Houdt JK. GBSX: a toolkit for experimental design and demultiplexing genotyping by sequencing experiments. BMC Bioinformatics. 2015;16:73.

52. Li H, Durbin R. Fast and accurate short read alignment with BurrowsWheeler transform. Bioinformatics. 2009:25:1754-60.

53. Li H. A statistical framework for SNP calling, mutation discovery, association mapping and population genetical parameter estimation from sequencing data. Bioinformatics. 2011;27:2987-93.

54. Reference C: Bcftools. https://samtools.github.io/bcftools/. Accessed 3 Sept 2016

55. Obenchain V, Lawrence M, Carey V, Gogarten S, Shannon P, Morgan M. VariantAnnotation: a bioconductor package for exploration and annotation of genetic variants. Bioinformatics. 2014;30:2076-8.

\section{Publisher's Note}

Springer Nature remains neutral with regard to jurisdictional claims in published maps and institutional affiliations. 